\title{
Optimum Tilt Angle for Photovoltaic Solar Panels in Zomba District, Malawi
}

\author{
B. Kamanga, ${ }^{1}$ J. S. P. Mlatho, ${ }^{2}$ C. Mikeka, ${ }^{2}$ and C. Kamunda ${ }^{2}$ \\ ${ }^{1}$ Environmental Affairs Department, Ministry of Environment and Climate Change Management, P/Bag 394, Lilongwe, Malawi \\ ${ }^{2}$ Department of Physics and Electronics, Chancellor College, University of Malawi, P. O. Box 280, Zomba, Malawi
}

Correspondence should be addressed to J. S. P. Mlatho; stanmlatho@gmail.com

Received 17 August 2013; Accepted 28 November 2013; Published 9 January 2014

Academic Editor: Haricharan S. Reehal

Copyright (C) 2014 B. Kamanga et al. This is an open access article distributed under the Creative Commons Attribution License, which permits unrestricted use, distribution, and reproduction in any medium, provided the original work is properly cited.

\begin{abstract}
A study to determine the optimum tilt angle for installing photovoltaic solar panels in Zomba district, Malawi, has been conducted. The study determined the optimum monthly tilt angles of PV solar panels and the seasonal adjustments needed for the panels in order to collect maximum solar radiation throughout the year. In this study, global solar radiation (GSR) on four tilted surfaces was measured. The north-facing surfaces were titled at angles of $0^{\circ}, 15^{\circ}, 20^{\circ}$, and $25^{\circ}$. The GSR data was used to determine the daily and monthly optimum tilt angles for the PV panels. The optimum tilt angles were found to be $0^{\circ}$ or $25^{\circ}$ depending on the time of the year. From October to February, the optimum tilt angle has been determined to be $0^{\circ}$ and, from March to September, the optimum tilt angle is observed to be $25^{\circ}$. There are only two seasonal adjustments that are needed for PV solar panels in Zomba district and these should be carried out at the end of February and at the end of September. For fixed solar panels with no seasonal adjustments, the optimum tilt angle for the PV solar panels that are northfacing has been determined to be $25^{\circ}$.
\end{abstract}

\section{Introduction}

Non-renewable energy sources, such as fossil fuel, have been the major source of energy in many countries, including Malawi. But because of the problems associated with the use of these non renewable energy sources, there is a need for alternative energy sources that are sustainable and nonpolluting. Kalogirou [1] observed that solar energy offers one of the best solutions to the problem of climate change. It also offers the possibility of reducing high demand for grid electricity and shortage of cooking and heating energy in rural and poor-urban households [2]. Madhlopa [3] further observed that Malawi has abundant solar radiation for most of the year.

There are several ways in which solar energy is being used, either directly or indirectly [4]. For direct usage, solar energy can be used as thermal energy or indirectly by converting it into electrical energy using photovoltaic systems. For larger, utility-scale applications, solar energy can feed vast photovoltaic (PV) solar panel farms or can be concentrated to vaporize fluids or to run heat engines [5]. Photovoltaic (PV) solar panels are used to convert solar radiation directly into electricity. Among the many renewable energy alternatives, solar energy remains one of the most well-known and adaptable methods for producing heat and electricity [1]. The conversion of solar energy into electricity by the solar panels is affected by, amongst other factors, absorption and scattering of direct solar radiation (DSR) by the atmosphere, tilt angle of the PV solar panels, declination, and efficiency of the PV solar panels [6-8].

Solar energy is abundant in Malawi though locally measured data is not available for most locations. Internationally available remote sensed databases, however, provide sufficient data for most design purposes. Malawi receives maximum irradiation of $6.5 \mathrm{kWh} /$ day $/ \mathrm{m}^{2}$ to $7.0 \mathrm{kWh} /$ day $/ \mathrm{m}^{2}$ from September to October and a minimum irradiation of $4.3 \mathrm{kWh} / \mathrm{m}^{2} /$ day to $4.6 \mathrm{kWh} / \mathrm{m}^{2} /$ day from January to February or from June to July depending on the location. The solar energy resource in Malawi is thus well within the limits normally considered to represent technical and commercial exploitability [9]. Despite this, there have been many projects on photovoltaic systems in Malawi that have not succeeded [10]. This is partly because these systems are not competitive on the energy market that is dominated by fossil fuel. These photovoltaic systems have high capital 
cost and modest conversion efficiency and suffer from the intermittency of solar radiation. Fonash [11] argues that to increase the use of terrestrial solar photovoltaic energy, more efforts are needed to enhance cell energy-conversion efficiency, increase module lifetime, reduce manufacturing costs, reduce installation costs, and reduce the environmental impact of manufacturing and deploying solar cells. The development of new technologies with higher conversion efficiencies is one of the key requirements for enabling the deployment of photovoltaic systems at a large scale. High conversion efficiency of photovoltaic systems largely depends on how the direct solar radiation (DSR) is incident of the PV solar panels (tilt angle of the panels), latitude, and the day of the year. The latitude and the day of the year are factors which cannot be changed depending on the location. The efficiency of solar panels to convert the DSR to electrical energy thus largely depends on its tilt angle.

The optimum tilt angle (inclination) of solar collectors such as PV solar panels is important for conversion of solar radiation into heat or electricity $[12,13]$. The best way to achieve the optimum tilt angle is by using a tracking system. Tracking systems are usually expensive, need energy input for their operation, and cannot easily be made applicable to solar collectors such as PV systems [14]. It is for this reason that fixed PV systems are usually used.

There are recommended tilt angles of solar panels that are based on the sun's movement throughout the year that depends on the latitude of the location. In some cases, seasonal adjustments to the tilt angle may be necessary depending on the location of the area. Such information on the optimum tilt angles is normally based on data of the global solar radiation (GSR) for that particular area that is measured on tilted surfaces. Unfortunately for Malawi, such data is not available and all the installed solar panels have tilt angles based on the theoretical tilt angle. Thus there is always a need to determine the optimum tilt angles for various districts in Malawi. In this study, the optimum tilt angle $\left(\beta_{\text {opt }}\right)$ for PV solar panels in Zomba district, Malawi, was investigated. The study also determined the seasonal adjustments for the fixed PV solar panels that are needed for the panels to receive maximum solar radiation throughout the year.

\section{Method}

This section presents the description of the study area, the experimental setup used in the calibration of the pyranometers, and the experimental setup used in the measurement of the global solar radiation (GSR) on tilted surfaces.

The study was conducted at Chancellor College Meteorological Station in Zomba district, Malawi, located at latitude of 15.387 south and longitude of 35.338 east. Figure 1 shows the location of Zomba district in Malawi. The site was chosen because it has a stabilized DC power supply that is required for the data acquisition system and is away from shading that would affect the solar radiation incident on the pyranometers during certain periods of the day.

2.1. Calibration of the Pyranometers. Two types of solar pyranometers were used in this study. The first type is the

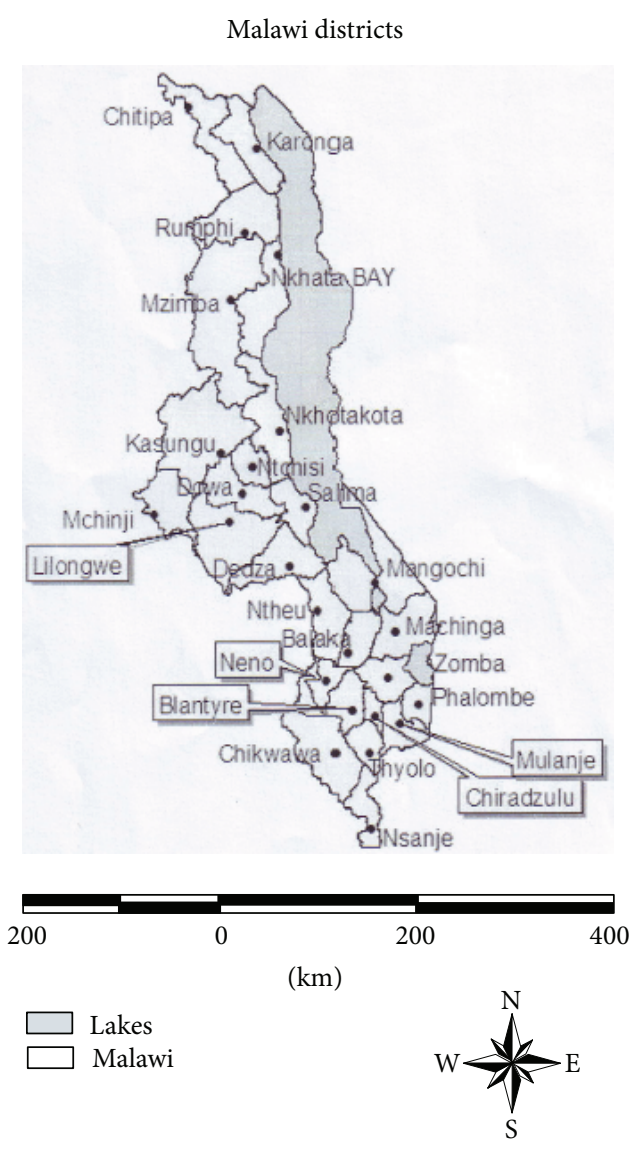

FIGURE 1: Map of Malawi showing the location of Zomba district in Malawi.

Eppley pyranometer, which is a standard instrument for measuring GSR on a plane surface. The Eppley pyranometer used has a calibration factor of $8.53 \times 10^{-6} \mathrm{~V} / \mathrm{Wm}^{-2}$ and the GSR measured was obtained by dividing the voltage produced by this pyranometer with this calibration factor.

The other pyranometer used is the LI-COR pyranometer that uses a LI190SB Quantum Sensor. The LI-COR Quantum Sensor produces a current when GSR is incident upon it. Thus in order to convert the current to voltage, a high precision $1 \Omega$ resistor is connected across its output terminals. Hence it is always necessary to relate the output voltage produced by the sensor to the DSR incident on the sensor. In this study, the three LI-COR pyranometers used were calibrated against the Eppley pyranometer in order to determine their calibration factors.

During the calibration process, three LI-COR pyranometers and an Eppley pyranometer were mounted on horizontal surfaces as shown in Figure 2. The four pyranometers were connected to a data logger, whose model is CR10X, that was powered by $12 \mathrm{~V}$ DC power supply. The four pyranometers were used to measure GSR throughout the day and the data logger was set to scan the channels to which the pyranometers were connected every 3 seconds for a period of ten minutes and a mean value of the readings was computed. Thus a mean value of the pyranometers was computed every ten minutes 


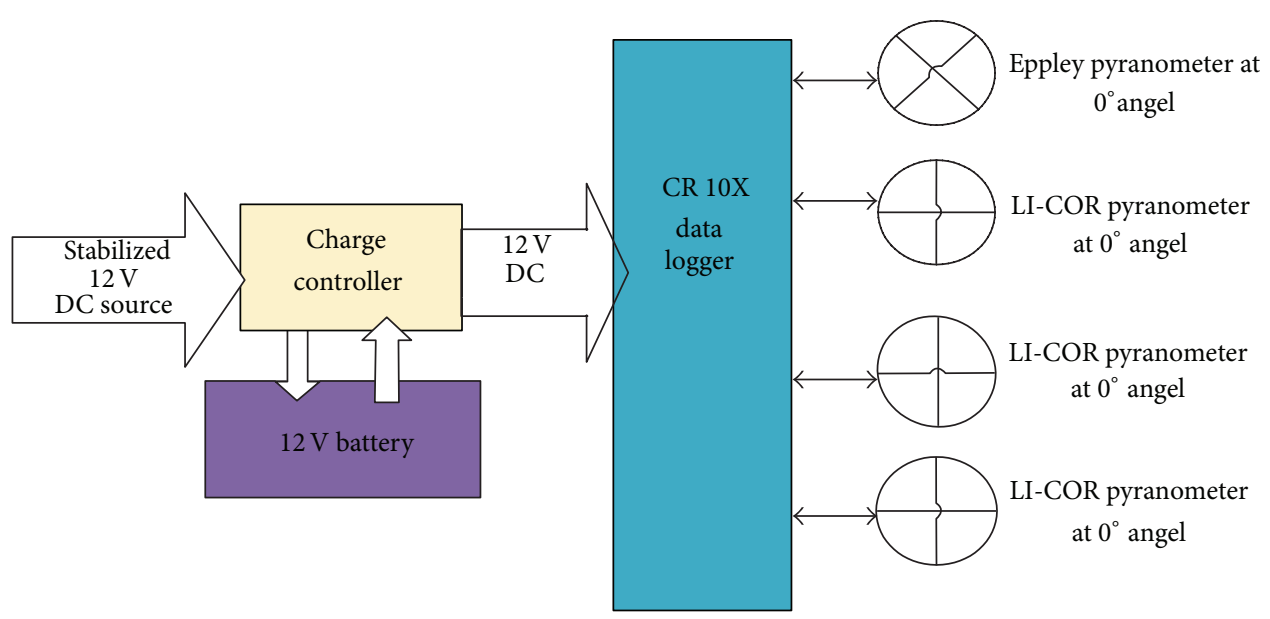

FIGURE 2: The experimental setup for calibration of LI-COR pyranometers.

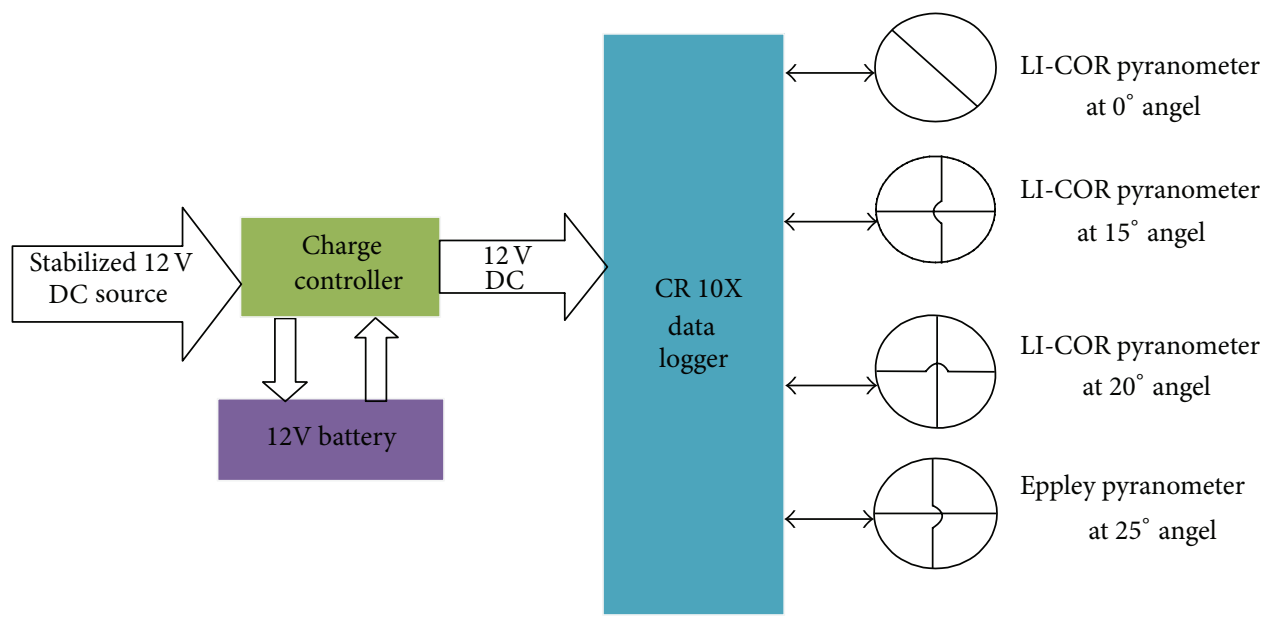

FIGURE 3: Experimental setup for GSR measurement.

throughout the day. The calibration process was carried out during the month of July, a period of clear skies.

Both the Eppley and the LI-COR pyranometers produce a voltage as an output when measuring the GSR. The calibration factor for the Eppley pyranometer was included in the data logger program so that it gave direct readings of the GSR. To determine the calibration factor of each LI-COR pyranometer, a graph of the GSR as measured by the Epply pyranometer was plotted against output voltage produced by the LI-COR pyranometer. A linear fit was fitted to the data in each plot in order to determine the calibration factor of the LI-COR pyranometer. The equation for the fitting line is given by

$$
y=a+b x,
$$

where $y$ is the GSR measured by the Eppley pyranometer, $a$ is intercept factor on the vertical axis, $b$ is the calibration factor $\left(\mathrm{kWm}^{-2}\right.$ per $\left.\mathrm{mV}\right)$ for the LI-COR pyranometer, and $x$ is the voltage produced by the LI-COR pyranometer. Ideally, $a$ should be zero.
2.2. Measurement of the Global Solar Radiation. After the calibration process, all the pyranometers were then used to measure the GSR at various tilt angles as shown in Figure 3. The four pyranometers were mounted onto plane surfaces that were tilted at angles of $0^{\circ}, 15^{\circ}, 20^{\circ}$, and $25^{\circ}$. The plane surfaces were north facing and were mounted $2 \mathrm{~m}$ above the ground to avoid ground reflected solar radiation and care was taken to ensure that they did not shade each other during the day. The angles were chosen with reference to Lunde [15] and Garg [16] who found the optimum tilt angle to be $\beta_{\mathrm{opt}}=\varphi \pm 15^{\circ}$. Furthermore, Duffie and Beckman [17] suggested that the optimum tilt angle is $\beta_{\text {opt }}=\left(\varphi+15^{\circ}\right) \pm 15^{\circ}$, and Heywood [18] concluded that it is $\beta_{\text {opt }}=\varphi+15^{\circ}$, where $\varphi$ is the latitude of the location and where plus and minus signs are used in winter and summer, respectively.

For the measurement of GSR, the data logger was programmed to collect hourly average data for a period of one year. For each hour, the data logger scanned its channels every 3 seconds and an average was computed for that hour. The daily GSR data was then calculated from the hourly average of the GSR data from the period of $6 \mathrm{am}$ to $6 \mathrm{pm}$ because 


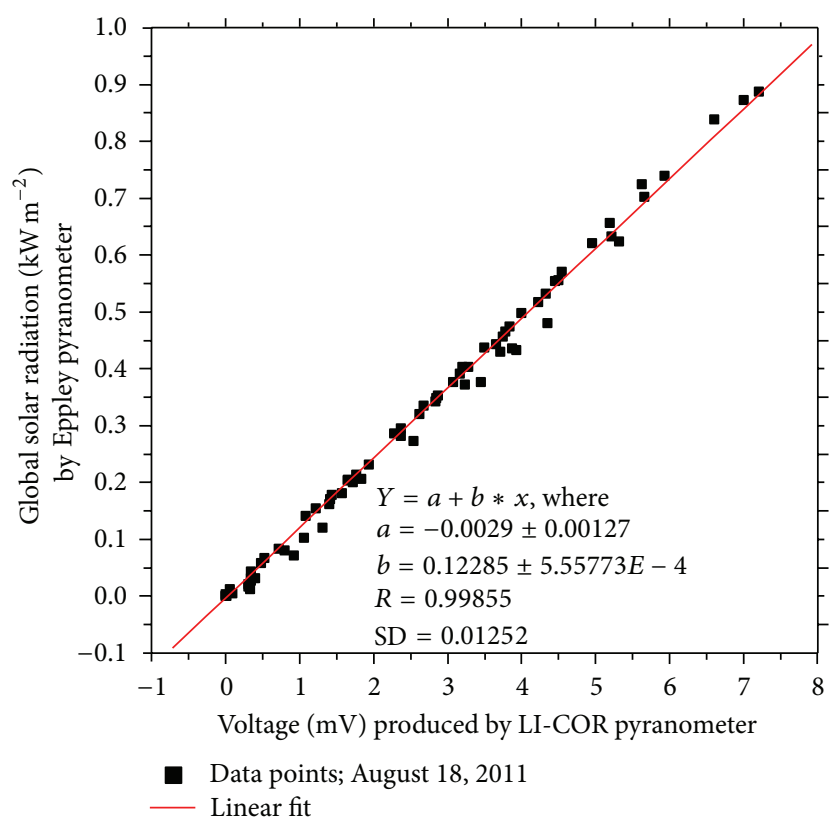

(a)

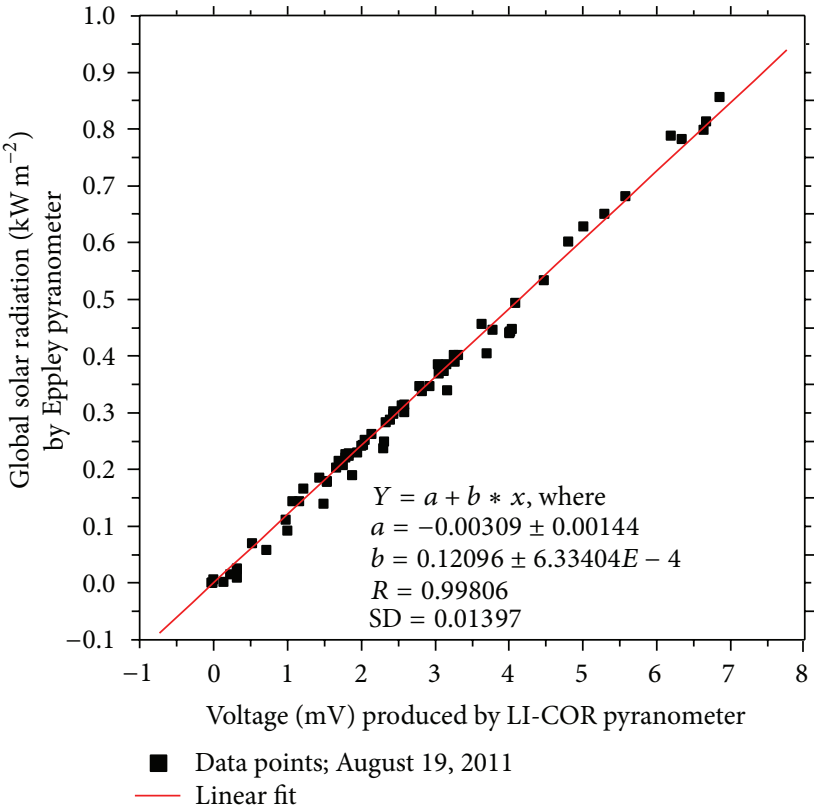

(b)

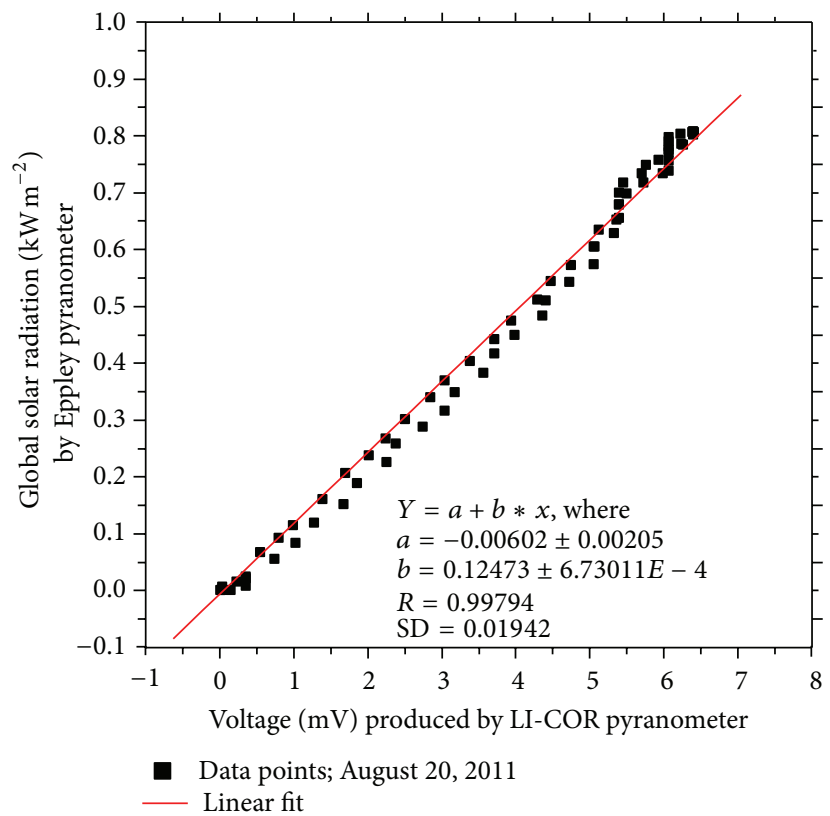

(c)

FIgURE 4: Solar radiation as obtained by the Eppley pyranometer plotted against the voltage produced by the LI-COR (serial number PHY32602).

this is the period during which significant solar radiation was available.

\section{Results}

This section presents results of the study. Presented first are the results on the calibration of the pyranometers and this is followed by the presentation of the results of the GSR measured on various tilted surfaces.
3.1. Calibration of Pyranometers. Figure 4 shows three plots of the calibration of LI-COR pyranometer with serial number PHY32602. This LI-COR pyranometer is hereafter referred to as LI-COR I. For each plot, the GSR measured by the Eppley pyranometer is plotted against the voltage produced by the LI-COR pyranometer.

A linear fit was fitted to the data in each plot in order to determine the calibration factor of the LI-COR pyranometer. The equation for the fitting line is given by (1) where ideally 
TABLE 1: Calibration factors for LI-COR pyranometers.

\begin{tabular}{|c|c|c|}
\hline Pyranometer & Parameter & Value \\
\hline \multirow{2}{*}{ LI-COR I (serial number PHY32602) } & Mean $a$ value & $4.00 \pm 1.6 \mathrm{Wm}^{-2} / \mathrm{mV}$ \\
\hline & Mean $b$ value (calibration factor) & $(1.237 \pm 0.006) \times 10^{-1} \mathrm{kWm}^{-2} / \mathrm{mV}$ \\
\hline \multirow{2}{*}{ LI-COR II (serial number PHY30406) } & Mean $a$ value & $-3.4 \pm 2.4 \mathrm{Wm}^{-2} / \mathrm{mV}$ \\
\hline & Mean $b$ value (calibration factor) & $(7.295 \pm 0.05) \times 10^{-2} \mathrm{kWm}^{-2} / \mathrm{mV}$ \\
\hline \multirow{2}{*}{ LI-COR III (serial number PHY32951) } & Mean $a$ value & $-3.8 \pm 1.4 \mathrm{Wm}^{-2} / \mathrm{m}$ \\
\hline & Mean $b$ value (calibration factor) & $(1.694 \pm 0.008) \times 10^{-1} \mathrm{kWm}^{-2} / \mathrm{mV}$ \\
\hline
\end{tabular}

$a$ should be zero. All three plots in this figure have $a$ values (intercept factor on the vertical axis) that are very close to zero and this indicates good fits. The mean value of $a$ is -4.00 $\pm 1.57 \mathrm{kWm}^{-2} / \mathrm{mV}$. All plots in the figure have small value of the standard deviations (SD) and have $R$-values that are close to 1.0 and this further indicates good linear fits. The mean value of $b$, which is the calibration factor for the LI-COR I, is $1.2370 \times 10^{-1} \pm 6.2071 \times 10^{-4} \mathrm{kWm}^{-2} / \mathrm{mV}$.

A similar calibration was carried out for the other two LICOR pyranometers and a summary of the results is shown in Table 1 .

Table 1 shows that all the linear fits for the calibration process have small values of the standard deviations (SD) and have $R$-values that are close to 1.0, which further indicates good linear fits.

3.2. Optimum Tilt Angle of the Solar Panels for Each Month. The installation of solar panels at any location requires that they are tilted towards the sun. In this study, GSR data was measured at one horizontal surface and three tilted surfaces that were facing north for months of September 2011 to August 2012. For each day, the hourly average of the GSR $\left(H_{\text {hour }}\right)$ was recorded. Thus the GSR average for each day $\left(H_{\text {day }}\right)$ was obtained by using

$$
H_{\text {day }}=\frac{\sum_{i=1}^{n} H_{\text {houri }}}{n} \text {, }
$$

where $n$ is the total number of hours of sunshine for each day.

The monthly average for the GSR was obtained from the daily averages by using

$$
H_{\text {month }}=\frac{\sum_{i=1}^{N} H_{\text {day } i}}{N},
$$

where $N$ is the total number of days for each month.

The monthly averages of the GSR were further used to determine the optimum tilt angle for the month.

For the month of September, shown in Figure 5(a), the pyranometer at an angle of $25^{\circ}$ measures the highest amount of GSR, seconded by the one at the angle of $20^{\circ}$. However, at the end of September, the trend changes as the pyranometer installed at the angle of $0^{\circ}$ measures the highest amount of GSR compared to the other three pyranometers. During this time, the sun is moving from the northern hemisphere to southern hemisphere. When the sun is in the northern hemisphere the highly tilted surface in Malawi receives more GSR than that tilted at an angle of $0^{\circ}$ (horizontal). As the sun moves towards the southern hemisphere, the pyranometer with $0^{\circ}$ tilt angle starts to receive more GSR. The sun eventually attains vernal equinox around September 22 where it is overhead at the equator. At any given time, the Earth surface receives the most GSR at the latitude where the DSR strikes it at right angles (when the zenith angle, $\theta_{z}$, is zero). As the zenith angle increases, the same amount of GSR is spread over a large area, so the GSR per unit area decreases, and this explains why the pyranometer with a tilt angle of $0^{\circ}$ starts recording slightly more GSR than that at a tilt angle of $25^{\circ}$ as the sun moves towards southern hemisphere.

Figure 5(b) shows, at the beginning of October, that the pyranometers at the angles of $0^{\circ}$ and $25^{\circ}$ measured equal amounts of GSR because, in the southern hemisphere, periods close to September 22, there is a vernal equinox. However, the general pattern shows that pyranometer at an angle of $0^{\circ}$ measures the highest levels of GSR throughout the month and the difference increases further at the end of October. The trend of having the pyranometer on the horizontal surface (tilted angle of $0^{\circ}$ ) recording the highest GSR compared to the other pyranometers installed at the various angles continues during the month of November.

Figure 5(d) shows that in December the pyranometer on horizontal surface $\left(0^{\circ}\right)$ measures the highest GSR. This is because, in the southern hemisphere (where Malawi is located), there is solstice on December 22 where the sun is farthest south and the length of time between sunrise and sunset is the longest in the year. Thus the sun is overhead and the DSR which contributes a large part of the GSR is striking the pyranometer on a horizontal surface at a right angle; hence more GSR is measured. However, the amount of GSR measured by other pyranometers installed at angles of $15^{\circ}, 20^{\circ}$, and $25^{\circ}$ is significantly not different from each other in December.

Figures 6(a) and 6(b) show that the pyranometer on a horizontal surface measured the highest amount of GSR during the months of January and February. However, the trend changes at the end of the February where there is a transition of having the pyranometer at an angle of $25^{\circ}$ measuring the highest GSR than the other pyranometers. This transition is because it is the period when the sun crosses the Equator as the sun starts moving northward. This transition 


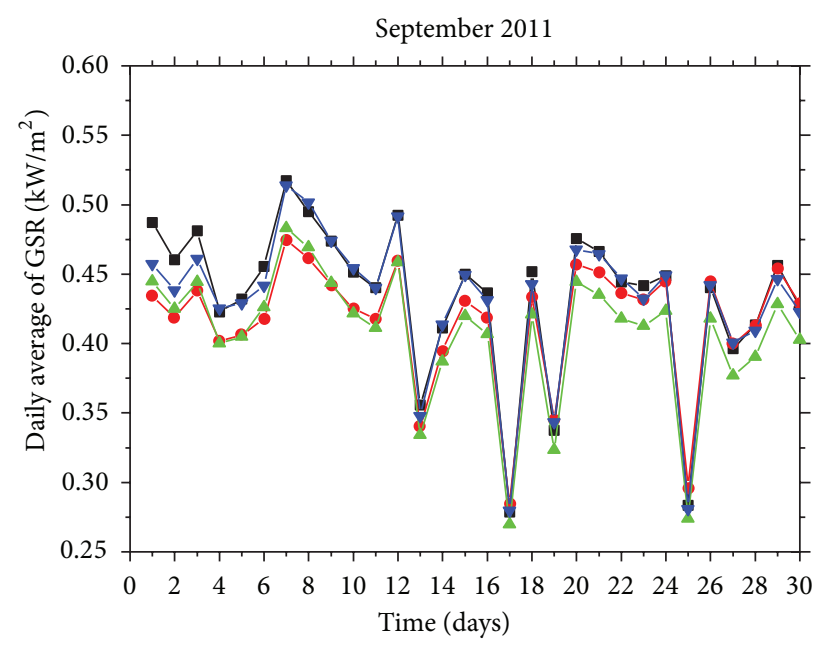

(a)

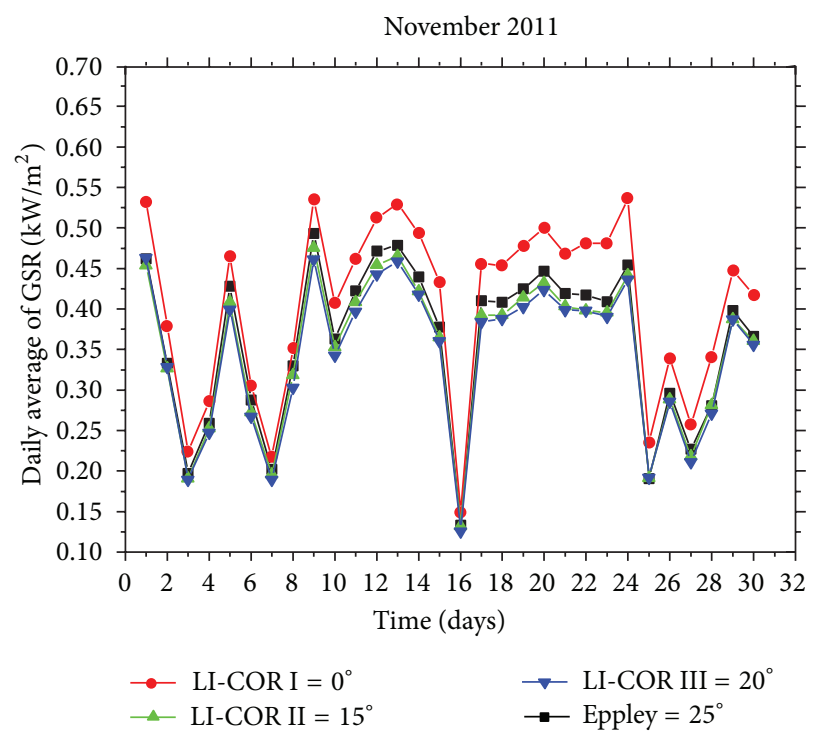

(c)

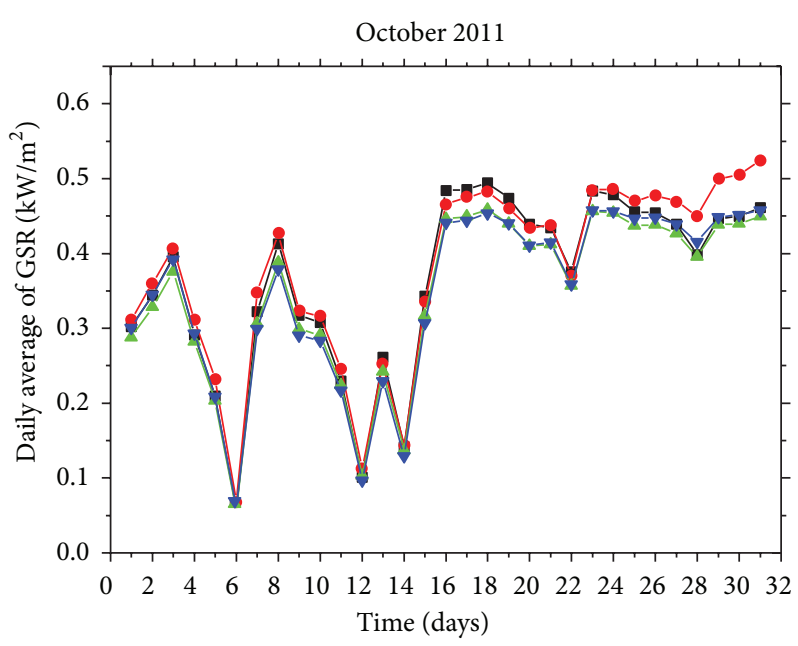

(b)

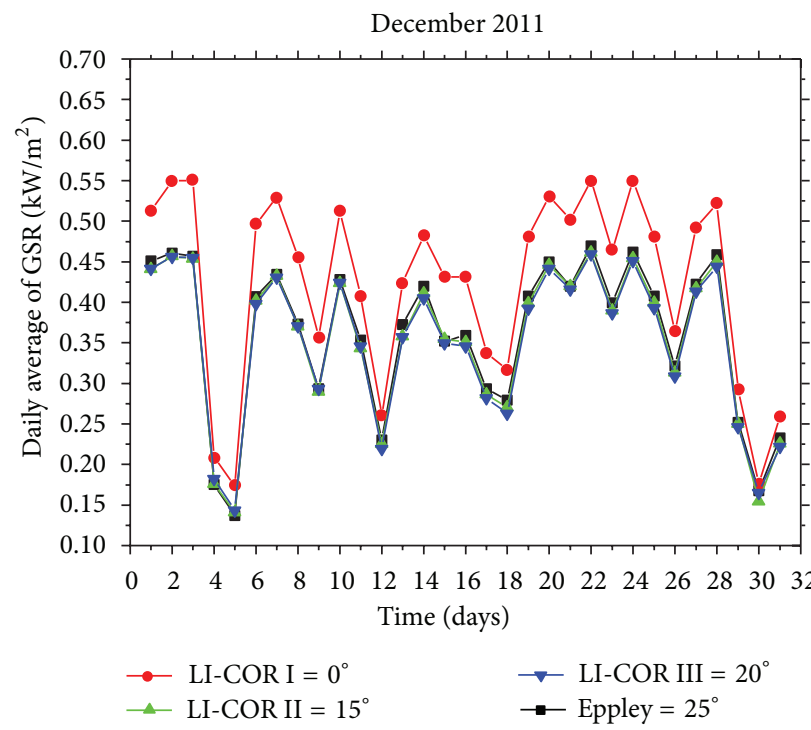

(d)

Figure 5: Global Solar radiation as measured on four surfaces at different angles $0^{\circ}, 15^{\circ}, 20^{\circ}$, and $25^{\circ}$ for the months of (a) September, (b) October, (c) November, and (d) December.

occurs up until mid-March and, during this transition, all the pyranometers measure almost equal amounts of GSR. This transition period suggests that the best time to make a seasonal adjustment of the tilt angle of the solar panel is from the end of February to mid March. Thus during this period, a solar panel with a tilt angle of $0^{\circ}$ should be adjusted to a tilt angle of $25^{\circ}$.

Figures 6(c) and 6(d) show that from mid March to the end of April, the pyranometer installed at an angle of $25^{\circ}$ measures the highest amount of GSR. This is because during this period, the sun crosses the Equator as it moves to the northern hemisphere and a surface with tilt angle of $25^{\circ}$ receives more GSR per unit area than the other pyranometers. This result agrees with the recommended theoretical angles by Lunde [15] who suggested that the tilt angle is plus $15^{\circ}$ of the latitude of the location in the winter if the latitude is above $15^{\circ}$.
All plots in Figure 7 show that the pyranometer at a tilt angle of $25^{\circ}$ records the highest levels of GSR during the months of May, June, July, and August. During this period, the sun is in the northern hemisphere and, on June 21 , the sun is farthest north and the length of time between sunrise and sunset is the shortest in the Southern hemisphere. Thus a pyranometer tilted at $25^{\circ}$ receives DSR at a small angle of incidence and this results in the highest GSR being measured. The pyranometer installed at the angle of $20^{\circ}$ records the second highest GSR and this is followed by that at an angle of $15^{\circ}$. The pyranometer on horizontal surface records the least GSR and this is because the sun rays are spread over a large area. Thus solar panels tilted at $25^{\circ}$ would receive the highest GSR as compared to those tilted at the other angles during these months. The drop of data for the pyranometer at $20^{\circ}$ during the months of June and July is because it was blown 


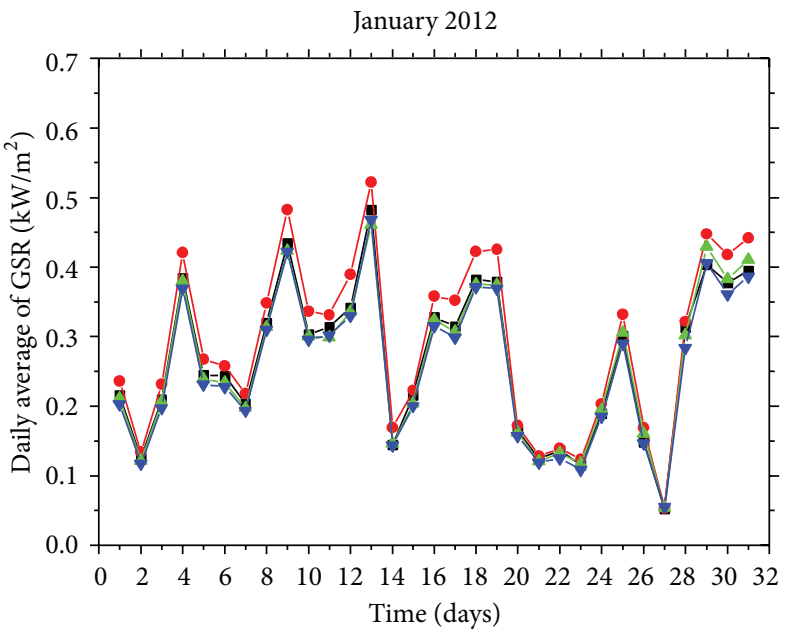

(a)

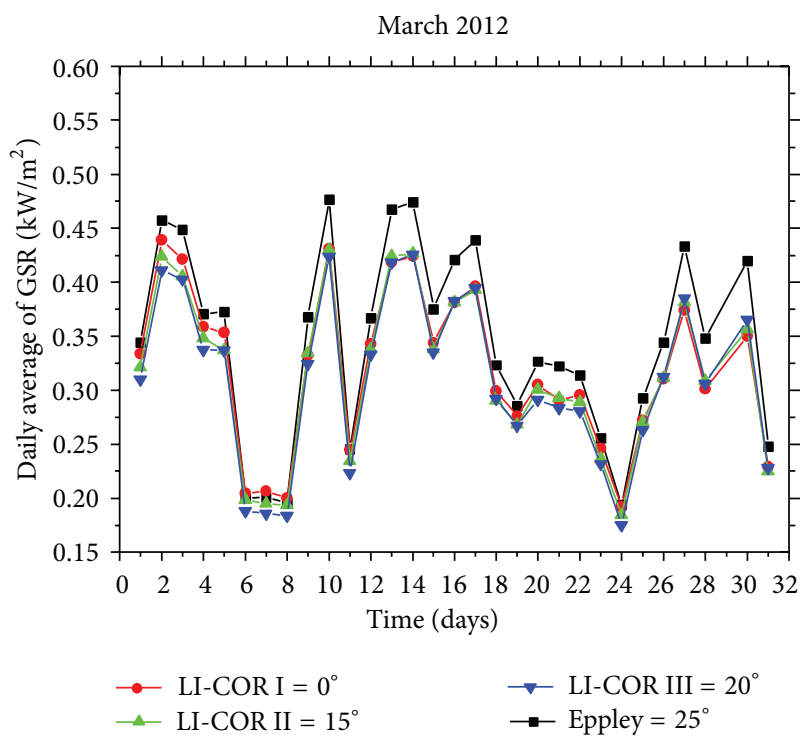

(c)

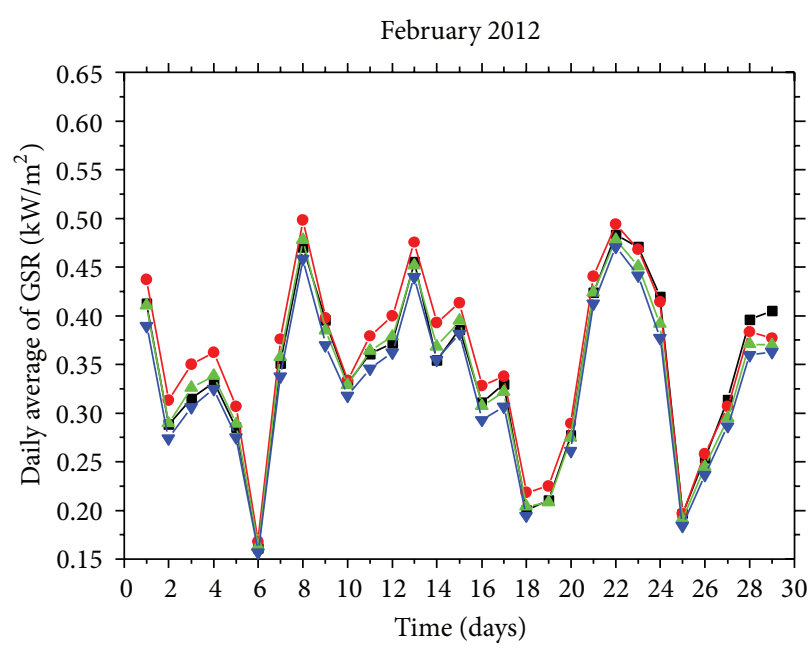

(b)

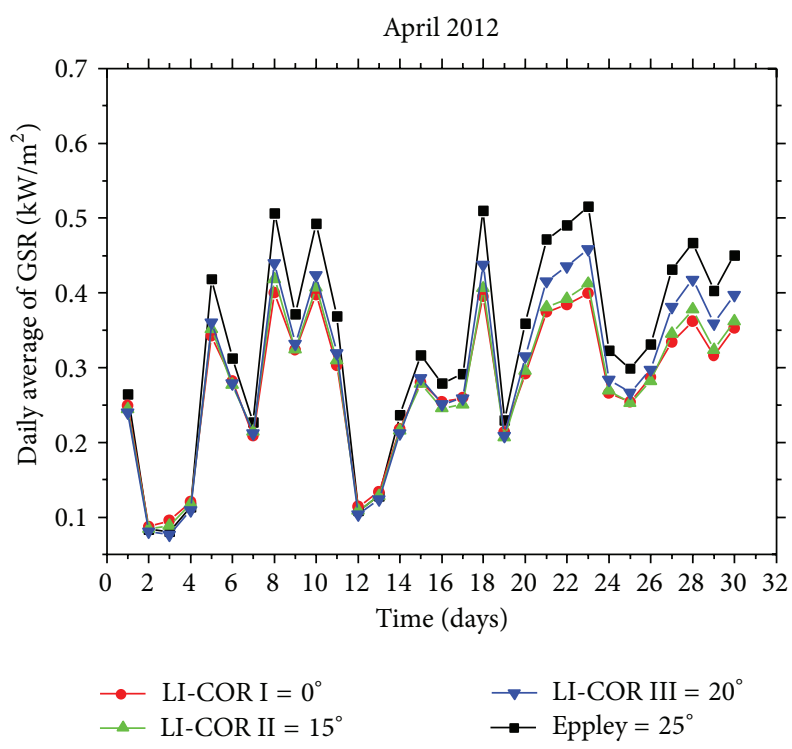

(d)

Figure 6: Global Solar radiation as measured on four surfaces at different angles $0^{\circ}, 15^{\circ}, 20^{\circ}$, and $25^{\circ}$ for the months of (a) January, (b) February, (c) March, and (d) April.

off the tilted surface by wind and hence it was measuring zero GSR. The pyranometer was corrected and replaced back on July 22, 2012 and started measuring the correct GSR.

3.3. Optimum Monthly Tilt Angle of Solar Panels in Zomba District. The various optimum tilt angles were determined for all months in a year and are shown in Table 2. The table indicates, from February to October, that the PV solar panels should be installed at a tilt angle of $0^{\circ}$, while the rest of the months of the year, the panels should be installed at a tilt angle of $25^{\circ}$. For the large part of the year, the optimum tilt angle has been determined to be $25^{\circ}$ and, in cases where it has not been the first optimum, it has been the second optimum tilt angle. Thus the data suggests that, for fixed PV solar panels in Zomba district, only two seasonal adjustments are needed.
TABLE 2: Optimum monthly tilt angle for solar panels in Zomba district.

\begin{tabular}{lcc}
\hline Month & First best angle & Second best angle \\
\hline September & $25^{\circ}$ & $0^{\circ}$ \\
October & $0^{\circ}$ & $25^{\circ}$ \\
November & $0^{\circ}$ & $25^{\circ}$ \\
December & $0^{\circ}$ & $25^{\circ}$ \\
January & $0^{\circ}$ & $25^{\circ}$ \\
February & $0^{\circ}$ & $25^{\circ}$ \\
March & $25^{\circ}$ & $0^{\circ}$ \\
April & $25^{\circ}$ & $20^{\circ}$ \\
May & $25^{\circ}$ & $20^{\circ}$ \\
June & $25^{\circ}$ & $20^{\circ}$ \\
July & $25^{\circ}$ & $20^{\circ}$ \\
August & $25^{\circ}$ & $20^{\circ}$ \\
\hline
\end{tabular}




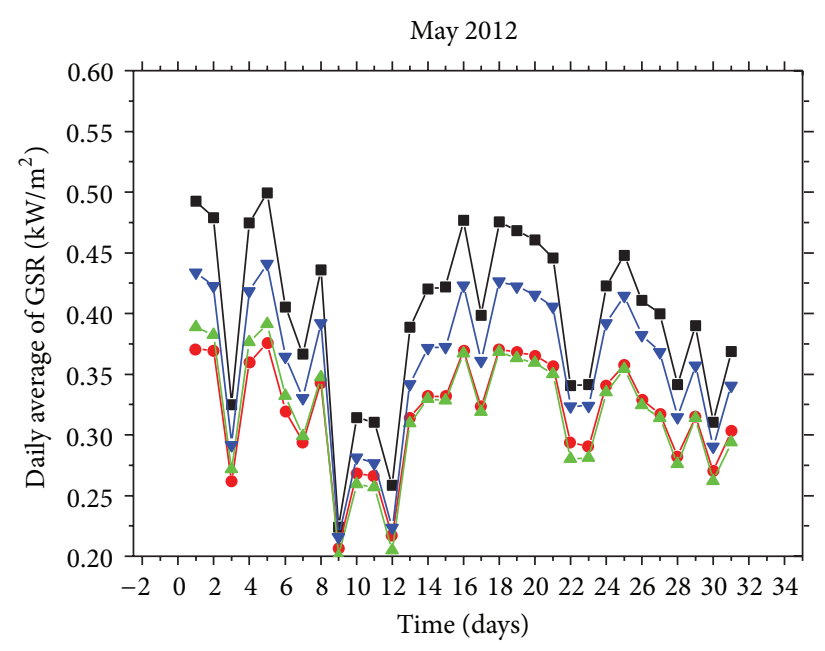

(a)

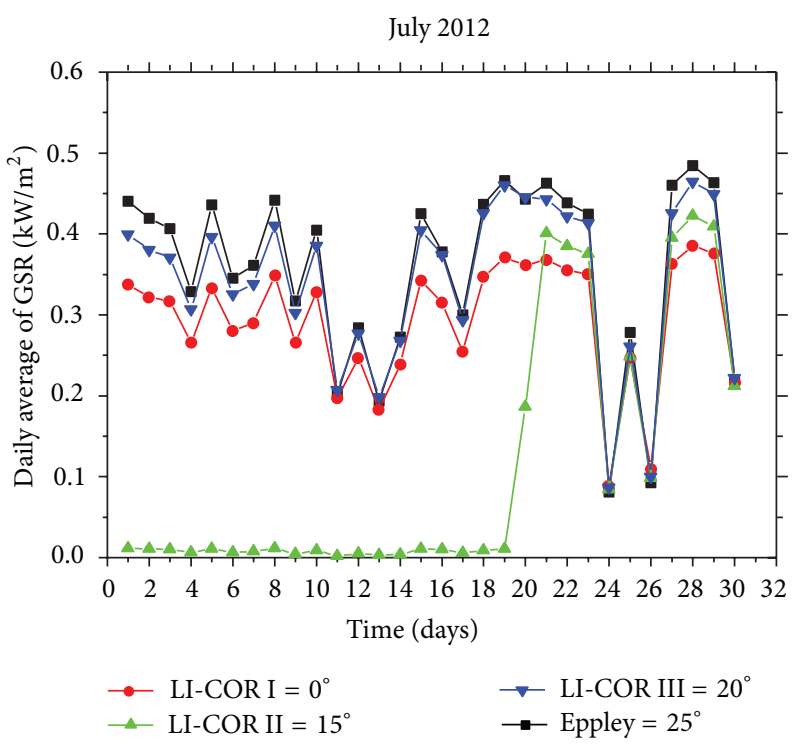

(c)

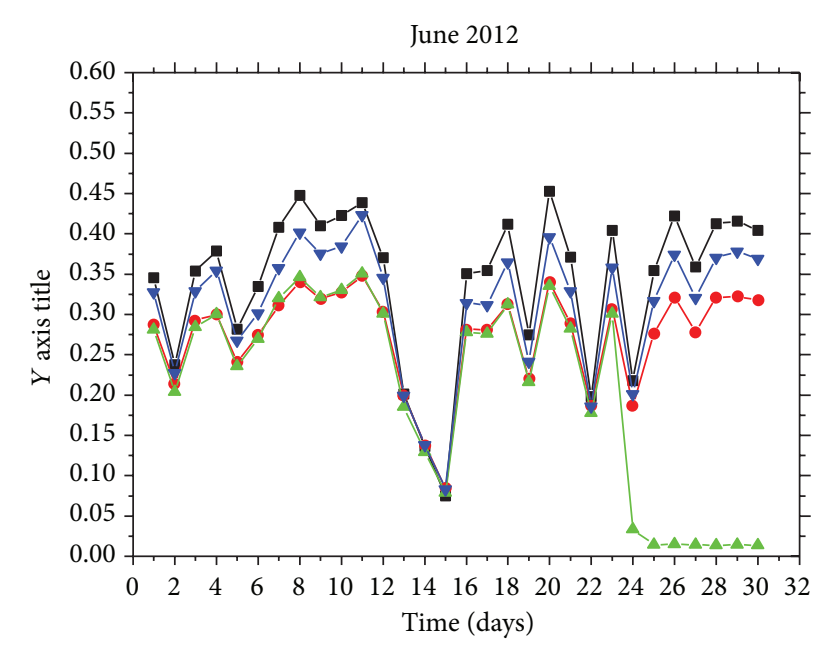

(b)

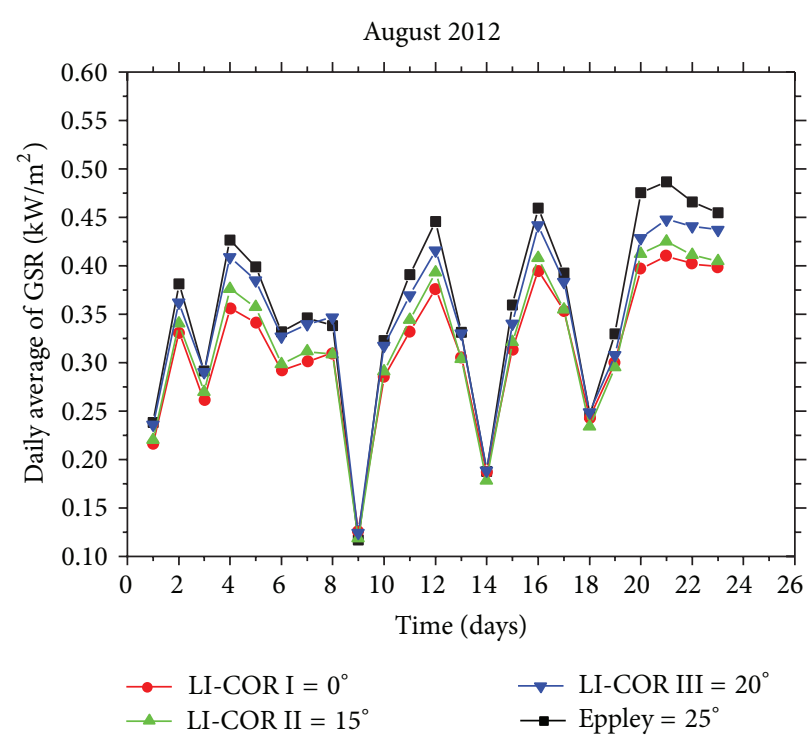

(d)

Figure 7: Global Solar radiation as measured on four surfaces at different angles $0^{\circ}, 15^{\circ}, 20^{\circ}$, and $25^{\circ}$ for the months of (a) May, (b) June, (c) July, and (d) August.

From Table 2, the seasonal adjustments to the fixed PV solar panels should be carried out in February and in September. At the end of February, the tilt angle should be adjusted from $0^{\circ}$ to $25^{\circ}$, while at the end of September, the tilt angle should be adjusted from $25^{\circ}$ to $0^{\circ}$.

Table 3 shows the yearly average of the GSR for the various pyranometers tilted at different angles. The tilt angle that gives the highest yearly average is the one at $25^{\circ}$. It is seconded by the tilt angle of $0^{\circ}$. Therefore for fixed solar panels with no seasonal adjustments, the optimum tilt angle to solar panels that should be north facing is $25^{\circ}$. The literature indicates that the best angle to tilt solar panels in a location with latitude of $\leq 15^{\circ}$ is equal to the latitude of that location. For locations with latitude $\geq 15^{\circ}$, the tilt angle should be equal to the latitude plus the $10^{\circ}[15]$. Thus these results agree with other previous studies. The T-statistic of the yearly means of the GSR for the
TABLE 3: Optimum yearly-tilt angle for the solar panels in Zomba district.

\begin{tabular}{lcc}
\hline Pyranometer & Tilt angle & Yearly average $\left(\mathrm{kW} / \mathrm{m}^{2}\right)$ \\
\hline LICOR S1 & $0^{\circ}$ & $0.3397 \pm 0.1037$ \\
LICOR S2 & $15^{\circ}$ & $0.3010 \pm 0.1230$ \\
LICOR S3 & $20^{\circ}$ & $0.3352 \pm 0.0988$ \\
EPPLEY & $25^{\circ}$ & $0.3547 \pm 0.1050$ \\
\hline
\end{tabular}

$0^{\circ}$ and $25^{\circ}$ tilt angles shows that the two GSR averages are significantly different at the significant level of 0.1 .

\section{Conclusion}

The optimum tilt angle for the solar panels in Zomba district has been determined for each month. The optimum tilt angle 
has been determined to be $0^{\circ}$ from October to February and to be $25^{\circ}$ from March to September. Thus there are only two seasonal adjustments that are needed for tilting solar panels in Zomba districts. The adjustments should be carried out at the end of February (from a tilt angle of $0^{\circ}$ to that of $25^{\circ}$ ) and at the end of September (from a tilt angle of $25^{\circ}$ to that of $0^{\circ}$ ). In cases where the PV solar panels are fixed with no seasonal adjustments, the tilt angle for the solar panels facing true north should be $25^{\circ}$.

\section{Nomenclature}

$\beta_{\text {opt }}: \quad$ Optimum tilt angle

$H_{\text {hour: }}$ Average global solar radiation for an hour

$H_{\text {daily }}$ : Average global solar radiation for a day

$H_{\text {month }}$ : Average global solar radiation for a month

$\varphi$ : $\quad$ Latitude

PV: $\quad$ Photovoltaic

GSR: Global solar radiation

DSR: Direct solar radiation.

\section{Conflict of Interests}

The authors declare that there is no conflict of interests regarding the publication of this paper.

\section{Acknowledgment}

The first author is grateful to the Malawi Environmental Endowment Trust (MEET) in Malawi for providing financial support for his scholarship.

\section{References}

[1] S. A. Kalogirou, "Solar thermal collectors and applications," Progress in Energy and Combustion Science, vol. 30, no. 3, pp. 231-295, 2004.

[2] D. H. W. Li and T. N. T. Lam, "Determining the optimum tilt angle and orientation for solar energy collection based on measured solar radiance data," International Journal of Photoenergy, vol. 2007, Article ID 85402, 9 pages, 2007.

[3] A. Madhlopa, "Solar radiation climate in Malawi," Solar Energy, vol. 80, no. 8, pp. 1055-1057, 2006.

[4] P. Roth, A. Georgiev, and H. Boudinov, "Design and construction of a system for sun-tracking," Renewable Energy, vol. 29, no. 3, pp. 393-402, 2004.

[5] R. Dong, Optimizing reflection and orientation for bifacial photovoltaic modules [thesis presented in partial fulfilment of the requirements for graduation], Department Mechanical Engineering, Ohio State University, 2009.

[6] Bosshard, "An assessment of solar energy conversion technologies and research opportunities," Technical Assessment Report, Global Climate and Energy Project, Stanford University, 2006, http://gcep.stanford.edu.

[7] O. S. Idowu, O. M. Olarenwaju, and O. I. Ifedayo, "Determination of optimum tilt angles for solar collectors in lowlatitude tropical region," International Journal of Energy and Environmental Engineering, vol. 4, article 29, 2013.
[8] E. Calabrò, "An algorithm to determine the optimum tilt angle of a solar panel from global horizontal solar radiation," Journal of Renewable Energy, vol. 2013, Article ID 307547, 12 pages, 2013.

[9] C. Tenthani, C. C. Kaong, I. B. M. Kosamu, and E. Phiri, The Role of Renewable Energy in Combating Climate Change-The Case of Malawi, The Polytechnic, University of Malawi, 2011.

[10] Government of Malawi, National Energy Policy, Government of Malawi, Lilongwe, Malawi, 2003.

[11] J. S. Fonash, Solar Cell Device Physics, Elsevier printing press, Oxford, UK, 2nd edition, 2010.

[12] S. Beringer, H. Schilke, I. Lohse, and G. Seckmeyer, "Case study showing that the tilt angle of photovoltaic plants is nearly irrelevant," Solar Energy, vol. 85, no. 3, pp. 470-476, 2011.

[13] E. J. Mahdi, S. N. Abdul-Wahid, S. S. Abdulstar, S. A. Sahab, and A. H. Mosli, "Optimum orientation of solar panels in Baghdad city," Journal of Basrah Researches, vol. 37, no. 3, p. 1, 2011.

[14] J. M. Ahmad and G. N. Tiwari, "Optimization of tilt angle for solar collector to receive maximum radiation," The Open Renewable Energy Journal, vol. 2, pp. 19-24, 2009.

[15] P. J. Lunde, Solar Thermal Engineering, Wiley, New York, NY, USA, 1980.

[16] H. P. Garg, Treatise on Solar Energy, vol. 1 of Fundamentals of Solar Energy, Wiley, New York, NY, USA, 1982.

[17] J. A. Duffie and W. A. Beckman, Solar Engineering of Thermal Processes, Wiley Interscience Publication, New York, NY, USA, 3rd edition, 2006.

[18] H. H. Heywood, "Operating experiences with solar water heating," Journal of Installation Heat Venting Energy, vol. 39, pp. 63-69, 1971. 


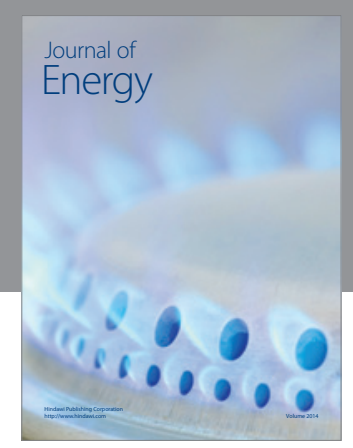

Journal of

Industrial Engineering
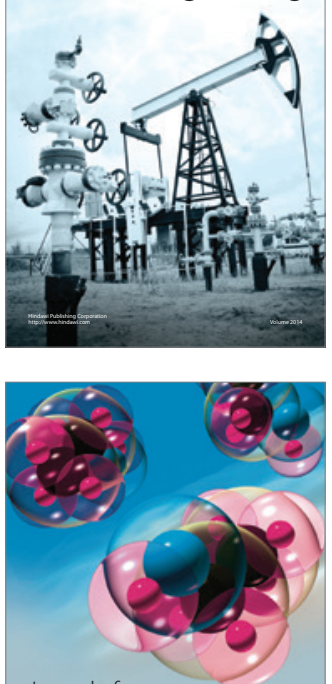

Fuels
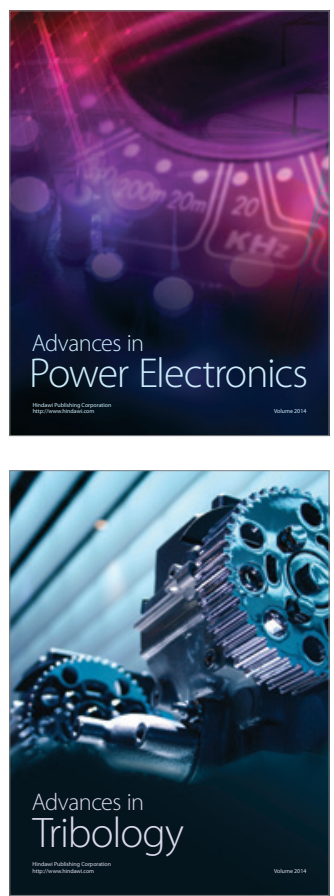

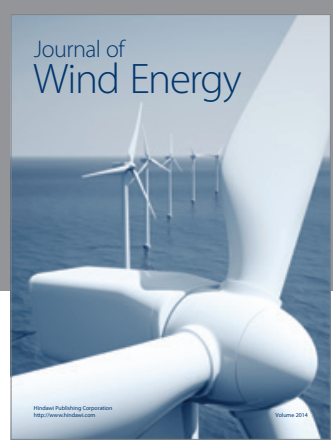

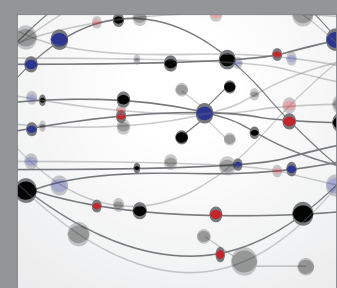

The Scientific World Journal

Submit your manuscripts at http://www.hindawi.com

Journal of

Structures
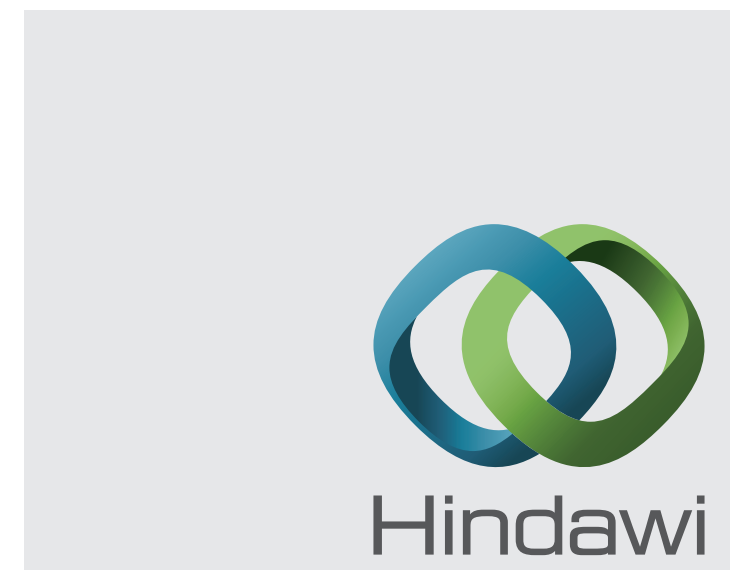

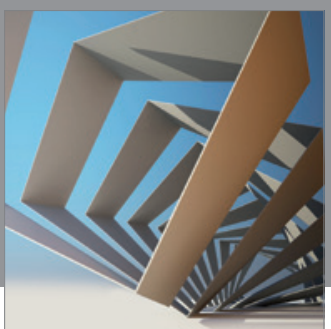

Rotating

Machinery
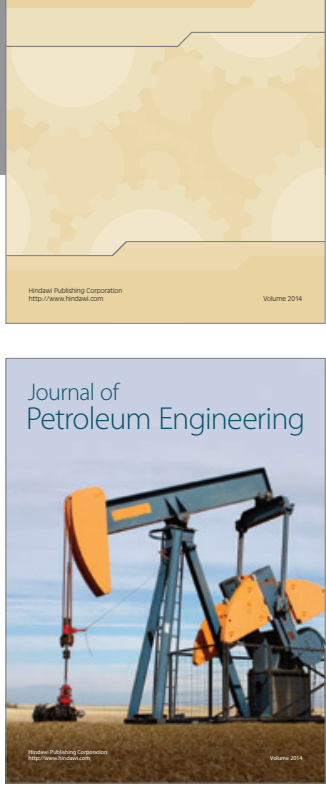

Journal of

Solar Energy
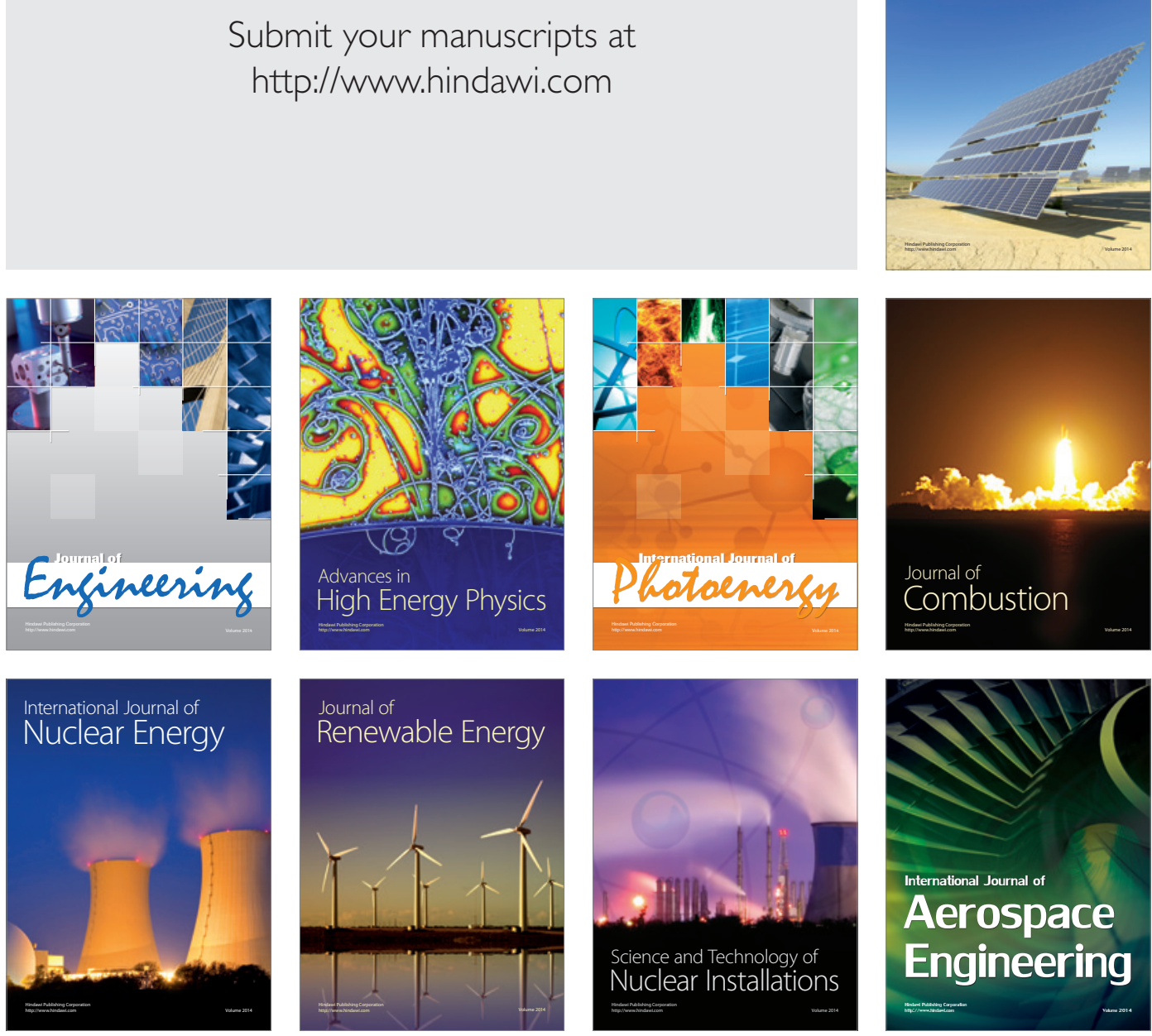